Systematic Review

\title{
The Effect of Clinical Supervision on Nurse Performance
}

\section{Rahayu Tri Nuritasari, Erfan Rofiqi, Tan Nina Fibriola and Rizal Tri Ardiansyah}

Faculty of Nursing, Universitas Airlangga, Surabaya, Indonesia

\begin{abstract}
Introduction: The nursing department often incurs problems about the performance of the nurses in providing nursing care at the hospital. This condition must get the attention of the head of the room as the manager who is directly responsible for the nursing care provided by the implementing nurse. Supervision is a part of the directional function that has the role of maintaining the department so then all programmed activities can be carried out properly and smoothly.
\end{abstract}

Methods: This systematic review was conducted to review the effect of clinical supervision on nurse performance. For the systematic review, a literature search of the PubMed, SAGE, Science direct, and Scopus databases using the keywords 'nursing', 'clinical supervision', 'clinical performance' and 'nurse performance' was conducted in February 2019. The search identified 15 relevant research articles from the 2.436 original articles and full texts published between 2013 and 2019.

Results: The results show that clinical supervision has the potential to improve staff performance, which will ultimately affect the successful attainment of the hospital.

Conclusion: Support from the hospital nursing management in providing support and monitoring is critical to the continuity, sustainability and successful implementation of clinical supervision. Clinical supervision activities conducted regularly in a scheduled manner will spur on the nurse's performance.

\section{ARTICLE HISTORY}

Received: December 26, 2019

Accepted: December 31, 2019

\section{KEYWORDS}

clinical supervision; nurse; performance;

\section{CONTACT}

Rahayu Tri Nuritasari

$\triangle$ rahayu.tri.nuritasari-

2018@fkp.unair.ac.id

$\fallingdotseq$ Faculty of Nursing, Universitas

Airlangga, Surabaya, Indonesia

Cite this as: Nuritasari, R. T., Rofiqi, E., Fibriola, T. N. \& Ardiansyah, R. T. (2019). The Effect of Clinical Supervision on Nurse Performance Jurnal Ners, 14(3si), 161-164. doi:http://dx.doi.org/10.20473/in.v14i3(si).16956

\section{INTRODUCTION}

Nursing services in hospitals depend on the nursing care given to individuals, their family and the wider communities. The process of nursing care is a part of the health services that is used a mirror of success which can affect the image of the hospital. The nursing department often incurs problems with the performance of the nurses in relation to providing nursing care in the hospital. This condition must get the attention of the head of the room as the manager who is directly responsible for the nursing care provided by the implementing nurse. Supervision is a part of the directional function that has the role of maintaining quality so then all of the programmed activities can be carried out properly and smoothly. Supervision in nursing is not just about control. Supervision activities include determining the conditions or personal and material requirements needed to achieve the objective of effective and efficient nursing care(Nursing supervision, 2016). Clinical supervision is becoming a standard practice for health professionals and it has been considered to be an important component of comprehensive clinical governance(Pearce, Phillips, Dawson, \& Leggat, 2014).

Clinical supervision involves a supportive relationship between the supervisor and supervisee that facilitates reflective learning. It is a part of professional socialization. The model of nursing clinical supervision in Indonesia is unclear as to the nature of the implementation in the hospital. Up to this point, it is not yet known how appropriate and practical the model is that can be applied(Yuswanto, Ernawati, \& Rajiani, 2018a). Researchers have developed methods to measure the effectiveness of clinical supervision using scales such as the Manchester Clinical Supervision Scale (MCSS) based 
on the commonly cited Proctor's model of clinical supervision which is a three function interactive model of the restorative, formative and normative aspects of the supervision relationship. Scales such as MCSS were designed to evaluate the processes and effectiveness of clinical supervision. However, they do not specifically evaluate the content of the sessions(Pearce et al., 2014).

Some studies concluded that one of the factors that influences nursing performance is supervision. Applying proper supervision will cause the implementing nurses to feel accepted, valued and involved so then there is a high commitment to advancing the nursing services as a whole(Cruz, Carvalho, \& Sousa, 2014).

The aim of this systematic review was to evaluate the current evidence regarding the effect of clinical supervision on nurse performance. The results may contribute to improving the existing clinical supervision practices for the health professionals.

\section{MATERIALS AND METHODS}

\section{Search strategies}

Reviewer search for articles published from 2012 to 2019 using the PubMed, Science Direct, SAGE, and Scopus databases. The keywords used were 'supervision', 'clinical supervision', 'nurse performance' and 'clinical performance'. In addition, only studies written in English were used for the current study. The search results in the form of titles and abstracts were the responsibility of the author in terms of reading and selecting the articles that were relevant to the criteria set by the author.

\section{Selection criteria}

The inclusion criteria were as follows: 1) including an increase in nursing services or a system developed as a part of nursing; 2) the subjects of the study were nurses, clinical supervision or nurse performance and 3) the location of the study was in a hospital or in education. The exclusion criteria were 1) focusing on the location in the community and 2) the research was a thesis or as part of a conference.

\section{Data extraction}

From the 15 studies that we chose, we extracted the type of research, the research subjects and the research data sources. The research subject in the 15 studies could be on clinical supervision and nurse performance. In addition, we extracted the results of the articles that discussed the influence between clinical supervision and nurse performance. The discussion of the differences in the research results required consideration from the author.

\section{RESULTS}

\section{Selection of studies}

The initial search retrieved a total of 2.436 studies: $32 \%$ from PubMed, 29\% from ScienceDirect, 15\% from SAGE and $24 \%$ from Scopus. From this, 2234 or $92 \%$ of the articles were deleted. Based on the inclusion and exclusion criteria, the author reviewed each article and reached a consensus regarding any exceptions. The review process for the selected articles developed in 3 stages; a title review, abstract review and full text review. We extracted 202 or $8 \%$ studies from the abstract titles and reviews and 102 or $4 \%$ studies from the full text review. Finally, a total of 17 articles were selected for this study. The retrieval and screening process has been summarized in Figure 1.

\section{Study methods}

Based on the research subject, there were 1808 respondents with the details available for as many as 1546 of the respondents. The supervisees totaled as many as 194; 23 had a Bachelor's degree, 10 had a Master's degree and the manager of nursing totaled as many as 68 respondents. Based on the location of the study, we found 17 studies that were conducted in hospitals. Based on the research design, we found 13 types of cross-sectional and reflective studies, in addition to randomized controlled trials, quasiexperiments, literature reviews, qualitative and comparative studies. We identified several instruments used to measure the Reflective Supervision, Self-Efficacy Scales for Supervisees (RSSESS), The Manchester Clinical Supervision Scale (MCSS) and The Brief Personal Survey (BPS), AMSN Mentoring Program-Mentor Guide book.

\section{DISCUSSION}

For this general hospital, the biggest influence on the nurses' performance occurs if all of the variables are intervened simultaneously. Ability contributes the most of the nurses' performance, followed by motivation and the nurses' health status. The supervision of the nursing services will benefit the nurses in terms of enhancing the feelings of support, reducing professional isolation, decreasing work and emotional fatigue, increasing job satisfaction and morale, and developing professional practices and support in practice. Furthermore, the supervision of the nursing services can improve the relationship of the nurses when they are supervised by their supervisors as well as in their relationships with other nurses.

Having established that clinical supervision is an important feature in the practice of nursing, it is important to state that there are times when it will not be successful. The barriers to successful clinical supervision may include the personalities of the people involved, skill mixtures, staffing levels and nurse caseloads. Clinical supervision is multifaceted and dynamic. Its outcome is dependent on many factors. However, there is increasing evidence suggesting that advantages can be achieved when and where quality clinical supervision is encouraged. Clinical supervision implementation is not only to monitor whether all nursing staff perform their duties as well as possible per the instructions or conditions outlined but it is also about how to improve the ongoing nursing process. 
Supervisors need to collaborate with the nurses when analyzing situations so then they can work together to be able to recognize, clarify and identify existing problems. In the identification stage, the supervisors and nurses work together when solving problems. The exploitation stage allows the nurse to feel that they have a quality relationship with their supervisor and they have a good perception of the supervisor. The supervisor can improve their knowledge and solve any problems faced by the nurses related to their nursing care documentation. The resolution stage explains that the nurse's needs have been noticed and there is a collaborative effort between the supervisor and the executing nurse.

Supervision of nursing services will benefit the nurses in enhancing feelings of support, reducing professional isolation, decreasing work and emotional fatigue, increasing job satisfaction and morale, and developing professional practice and support in practice. Furthermore, the supervision of nursing services can improve the relationship of the nurses supervised by their supervisors as well as their relationships with other nurses. This study has been able to identify the effect of clinical supervision on nurse performance. Four out of the fifty research studies showed that clinical supervision can improve the performance of the nurses and the research also found that the use of select strategies in the application of clinical supervision can enhance the performance of nurses in terms of their care documentation.

\section{CONCLUSION}

The study results show that the clinical supervision implementation is not only to monitor whether all nursing staff performs their duties as well as possible per the instructions or conditions outlined but it also shows how to improve the ongoing nursing process. The supervision of the nursing services will benefit the nurses in terms of enhancing their feelings of support, reducing professional isolation, decreasing work and emotional fatigue, increasing job satisfaction and morale and developing professional practice and support in practice.

\section{REFERENCES}

Aung, K. T., \& Jamal, N. Q. A. B. (2018). Nurse managers' perspectives on nurses' performance in mentorship program. Enfemeria Clinica, 28(Suplement 1), 139-143.

Brunero, S., \& Stein-Parbury, J. (2008). The effectiveness of clinical supervision in nursing : an evidenced based literature review. Australian Journal of Advanced Nursing, 25(3), 86-94.

Chaves, L., Mininel, V., Silva, J., Alves, L., Silva, M., \& Camelo, S. (2017). Nursing supervision for care comprehensiveness. Revista Brasileira de Enfermagem, 70(5), 1106-1111.

Cruz, S., Carvalho, A. L., \& Sousa, P. (2014). Clinical supervision: priority strategy to a better health. Procedia - Social and Behavioral Sciences, 112(7), 97-101.

https://doi.org/10.1016/j.sbspro.2014.01.1143

Escrig-pinol, A., Corazzini, K. N., Blodgett, M. B., Chu, C. H., \& McGilton, K. S. (2018). Supervisory relationships in long - term care facilities: A comparative case study of two facilities using complexity science. Journal of Nursing Management, 27(2), 311-319. https://doi.org/10.1111/jonm.12681

Estes, B. C. (2013). Abusive supervision and nursing performance. Nursing Forum, 48(1), 3-16.

Fitzpatrick, S., Smith, M., \& Wilding, C. (2012). Quality allied health clinical supervision policy in Australia: a literature review. Australian Health Review, 36(4), 461-465.

Frosch, C. A., Varwani, Z., Mitchell, J., Caraccioli, C., \& Willoughby, M. (2018). Impact of reflective supervision on early childhood interventionists' perceptions of self-efficacy, job satisfaction, and job stress. Infant Mental Health Journal, 39(4), 385-395. https://doi.org/10.1002/imhj.

Leggat, S. G., \& Phillips, B. (2015). Clinical supervision for allied health staff: necessary but not sufficient. Australian Health Review, 40(4), 431-437.

Lyu, D., Ji, L., Zheng, Q., Yu, B., \& Fan, Y. (2019). Abusive supervision and turnover intention: Mediating effects of psychological empowerment of nurses. International Journal of Nursing Sciences, 6(2), 98-203. https://doi.org/10.1016/j.ijnss.2018.12.005

Martin, P., Copley, J., \& Tyack, Z. (2014). Twelve tips for effective clinical supervision based on a narrative literature review and expert opinion. Medical Teacher, 36(3), 201-207. https://doi.org/10.3109/0142159X.2013.85216 6

Nancarrow, S. A., Wade, R., Moran, A., Coyle, J., Young, J., \& Boxall, D. (2014). Connecting practice: a practitioner centred model of supervision. Clinical Governance: An International Journal, 19(3), 235252. https://doi.org/10.1108/CGIJ-03-20140010

Nikpeyma, N., Saeedi, Z. A., Azargashb, E., \& Majd, H. A. (2014). Problems of clinical nurse performance appraisal system: a qualitative study. Asian Nursing Research, 8(1), 5-22.

Nursing supervision. (2016). 23(4), 7748. https://doi.org/10.7748/nop.2016.e815

Pearce, P., Phillips, B., Dawson, M., \& Leggat, S. G. (2014). Content of clinical supervision sessions for nurses and allied health professionals: A systematic review. Clinical Governance: An 
R. T. NURITASARI ET AL.

International Journal, 18(2), 39-154.

Proctor, B. (2015). Review : A randomised controlled trial of clinical supervision : selected findings from a novel Australian attempt to establish the evidence base for causal relationships with quality of care and patient outcomes, as an informed contribution to mental he. Journal of Research in Nursing, $15(2)$, 169-172. https://doi.org/10.1177/1744987109357819

Saxby, C., Wilson, J., \& Newcombe, P. (2015). Can clinical supervision sustain our workforce in the current healthcare landscape? Findings from a Queensland study of allied health professionals. Australian Health Review, 39(4), 476-482.

Yuswanto, T. J. A., Ernawati, N., \& Rajiani, I. (2018a). The effectiveness of clinical supervision model based on proctor theory and interpersonal relationship cycle (PIR-C) toward nurses' performance in improving the quality of nursing care documentation. Indian Journal of Public Health Research \& Development, 9(10), 561-566. https://doi.org/10.5958/0976-

5506.2018.01405.5

Yuswanto, T. J. A., Ernawati, N., \& Rajiani, I. (2018b). The effectiveness of clinical supervision model based on proctor theory and interpersonal relationship cycle (PIR-C) toward nurses' performance in improving the quality of nursing care documentation. Indian Journal of Public Health, 9(10), 562. 